Heliene Arantes CARVALHO (UEA) helienearantes@hotmail.com Silvana Andrade MARTINS (UEA) andrademartins.silvana2@gmail.com

\section{A expressão do aumentativo na fala manauara \\ aumentativo na fala}

\author{
The augmentative \\ graduation in the manauara \\ speech
}

CARVALHO, Heliene Arantes; MARTINS, Silvana Andrade. A expressão do aumentativo na fala manauara. Entrepalavras, Fortaleza, v. 7, p. 414-432, ago./dez. 2017.

Resumo: Este estudo analisa a expressão do aumentativo na fala manauara, no plano do conteúdo explícito e implícito como um recurso semântico-argumentativo que ultrapassa o enunciado. A base teórica se norteia na Sociolinguística Variacionista Laboviana (LABOV, 2008), na Teoria de Avaliatividade (MARTIN; WHITE, 2005) e no Funcionalismo Linguístico (SOUZA, 2012), observando os níveis gramaticais para o tratamento da expressão do grau aumentativo. Verifica-se a frequência de ocorrência e o tipo de uso na expressão do aumentativo, através de variáveis linguísticas e extralinguísticas. $\mathrm{O}$ corpus investigado pertence ao banco de dados do FAMAC (Fala Manauara Culta e Coloquial) e constituem-se de 6 registros, distribuídos equitativamente em EF, DID e D2. O critério de seleção dos informantes são os que tenham nascido em Manaus ou residam há mais de 20 anos. A análise dos dados apontou que a maior incidência de gradação do aumentativo ocorreu no tipo de registro DID, com $41 \%$ de frequência.

Palavras-chave:Fala manauara. Variação linguística. Aumentativo. Teoria da avaliatividade. Funcionalismo linguístico. 
Abstract: This study analyzes the augmentative graduation in the speech of Manaus, in the context of explicit and implicit content as a semantic-argumentative resource that goes beyond the utterance. The theoretical basis of this study is on Labovian Variationist Sociolinguistics (1972) (LABOV, 2008), on Theory of Appraisal (MARTIN; WHITE, 2005) and on Language Functionalism (SOUZA, 2012), observing grammatical levels for the treatment of augmentative graduation. The frequency of occurrence and the type of use in the augmentative graduation are verified through linguistic and extralinguistic variables. The investigated corpus belongs to the FAMAC database (Manauara and Colloquial Speech) and consists of six registers, distributed equally in EF, DID and D2. The criterion of selection of informants is for those who were born in Manaus or have lived there for more than 20 years. Data analysis indicated that the highest incidence of graduation occurred in the DID record type, with a $41 \%$ frequency.

Keywords: Manauara talk. Linguistic variation. Augmentative graduation. Appraisal system. Language functionalism.

\section{Introdução}

O uso da linguagem se manifesta no processo de interação social, por meio das práticas sociais. Cada enunciador constrói seu enunciado de acordo com a situação enunciativa, seu interlocutor, sua função social. Assim surgem novos itens lexicais, novas formas de ênfase, motivados por diferentes contextos sociais e por fatores externos.

Nesta perspectiva, o objetivo deste estudo é evidenciar os mecanismos de expressão do aumentativo que caracterizam a fala manauara em contextos de diálogos, entrevistas e elocuções formais. Busca-se verificar a natureza desses mecanismos, os quais podem ser lexicais, morfossintáticos, discursivos e prosódicos.

Este trabalho visa analisar a ocorrência da expressão do aumentativo explícito e implícito na fala manauara, como um processo cognitivo avaliativo do mundo, como um recurso argumentativo presente nos diversos níveis da língua, entendida no seu contexto comunicativo. Este projeto está vinculado ao grupo de pesquisa Fala Manauara Culta e Coloquial (FAMAC), sob a coordenação de Martins (2009), o qual tem tido uma repercussão muito positiva em referência aos estudos desenvolvidos sobre o falar da metrópole amazonense.

Este estudo fundamenta-se nos princípios teórico-metodológicos da Sociolinguística Variacionista (CALVET, 2002; LABOV, 2008), do Funcionalismo Linguístico (SOUZA, 2012; CUNHA, 2011) e do Sistema de Avaliatividade (MARTIN; WHITE, 2005). Busca-se confluir as duas primeiras teorias supracitadas, pois ambas possuem como objeto de estudo a língua em uso, compreendida como fato social e um inventário aberto. A terceira teoria complementa este estudo por focalizar o sistema 
V. 7 (2)

414-432 ago/dez 2017

de gradação por meio de uma concepção de grau que não se restringe ao âmbito exclusivo do enunciado, mas que o ultrapassa, compreendendo a situação discursiva e os diversos elementos que a caracterizam. Os processos de gradação/intensificação explícitos e implícitos são analisados no âmbito do enunciado e da enunciação, conjugando as interfaces da fonética, da morfossintaxe, da semântica e da pragmática (VIEIRA; VIEIRA, 2008).

\section{Quadro teórico norteador}

Nesta pesquisa, a teoria Sociolinguística Variacionista é essencial, pois estuda a língua em uso, considerando os aspectos sociais e culturais da produção linguística. Entender quais são as razões que impulsionam a variação linguística, quais são os contextos que favorecem a variação e quais são as probabilidades de ocorrências de uma variante em um mesmo grupo de falantes ou entre grupos de falantes distintos, segundo variáveis convencionais e considerando os tipos de registro é fundamental para este estudo.

Nesta perspectiva teórica, este estudo analisa a expressão do aumentativo na fala manauara, com a finalidade de evidenciar a congruência de fatores linguísticos e extralinguísticos nos processos cognitivos avaliativos do mundo na seleção dos mecanismos para indicar a gradação/intensificação de elementos que constam no discurso, no uso da língua no contexto social. Orienta-se pelo pressuposto teórico de que a língua é um instrumento de interação social e, com isso, analisamse as condições discursivas, para averiguar as diferentes motivações das estruturas linguísticas no uso dos mecanismos de expressão do aumentativo.

Para Souza (2012), a língua "tem funções cognitivas e sociais que desempenham um papel central na determinação das estruturas e dos sistemas que organizam a gramática de uma língua". Nesse sentido, emprega-se a teoria funcionalista para mostrar o dinamismo da língua devido à interação social. A língua é o meio de comunicação pelo qual uma pessoa pode expor seus sentimentos, pensamentos, opiniões, dialogar com o outro e denunciar a que classe social e/ou região pertence. Busca-se assim investigar a competência linguística do falante manauara na seleção dos mecanismos de expressão de gradação do aumentativo, considerando o contexto discursivo em que se insere. 
Os pressupostos teóricos do Sistema de Avaliatividade proposto por Martin e White (2005) complementam este estudo, pois averiguam como um indivíduo (falante/escritor), através do seu discurso, concebe e classifica um evento, um fato, um objeto ou um fenômeno. Esse sistema é composto por três subsistemas, os quais são a atitude, o engajamento e a gradação; somente esta última é selecionada para este estudo. A gradação perpassa a categoria de julgamento, pois pode indicar força e/ou foco. Nesse estudo, os dados que codificam a gradação são analisados seguindo a orientação teórica do sistema de avaliatividade no sentido mais amplo, sem se preocupar em fazer a distinção entre força e foco, vistos, portanto, como um só mecanismo de gradação. No entanto, entende-se que é importante apresentar uma definição do que se entende por força e foco. A força é composta pela intensificação e quantificação, que se realiza por meio de vários recursos léxicogramaticais, referente à gradação de processos, qualidades e indicadores de modalidades e, quanto à quantificação, aborda a gradação de entidades, "quer sejam elas concretas ou abstratas" (VIAN JÚNIOR, 2010, p. 198); e o foco refere-se à gradação de categorias semânticas prototípicas, sendo dividido em acentuação e atenuação, em que a primeira enfatiza a essência de categorias semânticas experienciais e a segunda pode "reduzir o grau de pertencimento de um item lexical a certa categoria experiencial e conseguir desta forma representá-lo como um membro menos 'autêntico' da categoria" (VIAN JÚNIOR, 2010, p. 202).

O grau pode ser manifestado de forma explícita e implícita, sendo observado e estudado nas formas do intensificador, indicados por afixos, junto a substantivos, adjetivos, advérbios e locuções adverbiais de intensidade para graduar qualidades, etc.

O grau avaliativo do substantivo está relacionado com o aspecto avaliativo que pode ser chamado de sufixo avaliativo. Rocha (2008) aponta o grau não só para indicar o tamanho, mas também para exprimir a afetividade e a emoção que o falante profere em seu discurso. Os sufixos avaliativos podem ser três: o primeiro é o sufixo subjetivo, em que expressa a subjetividade do falante; o segundo é o sufixo valorativo, o qual manifesta um julgamento de valor com relação a um referente, podendo ser positivo (melhorativo) ou negativo (pejorativo); e, por último, o sufixo dimensional, que está associado ao tamanho propriamente dito. Esta abordagem serve de apoio na análise dos sufixos avaliativos que expressam o grau aumentativo no corpus da fala manauara. 
v. 7 (2)

41.4-432 ago/dez 2017

418

\section{Breve conceito do grau aumentativo nas gramáticas normativas}

Segundo Bechara (2001, p. 140), o grau aumentativo no substantivo apresenta sua significação aumentada devido ao auxílio dos sufixos derivacionais. A derivação gradativa do substantivo pode ser comprovada através de dois processos, o sintético e o analítico. No processo sintético ocorre o acréscimo de um final especial chamado de sufixo derivacional aumentativo, como pode ser visto na palavra homenzarrão. Já o processo analítico "consiste no emprego de uma palavra de aumento (grande, enorme) junto ao substantivo" (BECHARA, 2001, p. 140), como pode ser visto em homem grande. Há o grau aumentativo afetivo no qual se pode submeter um sentido valorativo, ou seja, expor o desprezo, a crítica, a admiração, sempre em função da significação lexical da base, auxiliados por uma entoação especial e os entornos os quais envolvem falante e interlocutor.

No adjetivo, de acordo com Bechara (2001, p. 155), a gradação ocorre através do positivo, do comparativo e do superlativo. O positivo pode-se dizer que não é uma gradação, já que enuncia somente a qualidade, como "Este homem é cuidadoso". O comparativo estabelece uma comparação entre dois ou mais seres, o qual pode estabelecer uma igualdade, uma superioridade e uma inferioridade.

De acordo com Bechara (2001, p. 155), o superlativo sobrepuja a noção comum que temos de uma qualidade de um mesmo ser e ressalta a qualidade desse ser em relação aos outros. Quando o superlativo ressalta uma qualidade através de uma relação ou comparação, pode-se afirmar que o superlativo é relativo. Já quando o superlativo é ressaltado sem nenhuma relação com outros seres, chama-se de superlativo absoluto ou intensivo, o qual pode ser sintético ou analítico. No superlativo absoluto sintético, adquire-se o sufixo derivacional -íssimo (ou qualquer outro de valor intensivo) tornando mais enfático no aspecto semântico. Há o superlativo absoluto analítico, no qual se acrescenta uma palavra intensiva antes do adjetivo e, para obter a manifestação afetiva do superlativo, há a repetição do adjetivo ou do advérbio. A intensificação gradual dos advérbios segue as mesmas regras dos adjetivos, onde são expressas por estruturas sintáticas.

Na Novíssima Gramática da Língua Portuguesa, Cegalla (2008) explica o grau aumentativo na segunda parte de seu livro, na seção da morfologia. A flexão do grau aumentativo no substantivo é dita somente para exprimir as variações de tamanho dos seres. Mas, no quadro de 
observações, há um item que aborda o grau para exprimir a opinião do falante no sentido pejorativo ou depreciativo. Essa gramática trata o assunto de forma direta, normatizada, sem muitas explicações de como se chegou àquele entendimento, isto é, expõe o assunto de modo que o estudante seja capaz de memorizá-lo, sem precisar compreender o conteúdo.

Sobre o adjetivo com flexão de aumentativo, o gramático explicita ao dizer que "as formas aumentativas e diminutivas equivalem, geralmente, a superlativos" (CEGALLA, 2008, p. 154). Além disso, aponta que na linguagem emotiva e coloquial é "comum o emprego de adjetivos com as flexões próprias do aumentativo e do diminutivo" (CEGALLA, 2008, p. 154). Nota-se que nesta gramática não há explicações aprofundadas sobre a gradação, o assunto recebe tratamento superficial, diferentemente da Moderna Gramática Portuguesa, de Evanildo Bechara (2001).

Na Nova Gramática do Português Brasileiro, de Ataliba T. de Castilho (2014), a gradação dos adjetivos consta no tópico de semântica do adjetivo, no item "adjetivos predicativos", no subtópico "qualificadores". Nesta seção, o autor expõe que os qualificadores evidenciam as propriedades intencionais do adjetivo, que expressam a gradação. Na semântica do advérbio, a gradação é encontrada no tópico de advérbios qualificadores cujos subitens são semelhantes aos adjetivos qualificadores. Verifica-se que, nesta gramática, por seguir uma orientação teórica funcionalista, o conteúdo aumentativo é chamado de "gradação" e é tratado com mais profundidade, quando se compara com as outras gramáticas supracitadas, trazendo uma abordagem inovadora na exposição do assunto, com aporte da teoria da Linguística Funcionalista, no quadro das gramáticas do português contemporâneo.

\section{Procedimentos Metodológicos}

Este estudo seguiu os procedimentos teórico-metodológicos da Teoria Variacionista, a partir dos princípios estabelecidos por William Labov (2008) para a realização da pesquisa sociolinguística. O critério para a seleção dos sujeitos da pesquisa foi ter nascido em Manaus ou residir há mais de 20 anos neste município.

O corpus linguístico analisado constituiu-se de 6 inquéritos, formado por duas entrevistas entre informante e documentador (DID), dois diálogos (D2) e duas elocuções formais (EF). A transcrição de cada inquérito teve uma dimensão de 12 a 15 páginas digitalizadas. Esta foi uma estratégia empregada para estabelecer um equilíbrio quanto à quantidade 
v. 7 (2)

414-432 ago/dez 2017

de dados. Quanto aos assuntos dos registros, nas elocuções formais, foram registradas duas aulas de curso de graduação, sendo uma sobre o tema Dialetologia e a outra sobre Geografia. Nos diálogos entre documentador e informante, constaram-se duas entrevistas em que, na primeira, o tema foi moradia durante a infância e, na segunda, sobre as expectativas em relação ao casamento. No diálogo entre informantes, registraram-se duas conversas informais, uma realizada durante uma aula de Educação Física na Vila Olímpica, que versou sobre a própria aula e, a outra, que ocorreu na casa de uma das interlocutoras e versou sobre a vida de uma delas. Os corpora analisados pertencem ao Banco de Dados da Fala Manauara Culta e Coloquial (FAMAC), os quais são constituídos de inquéritos, subdivididos em três tipos de registros de fala: EF, DID e D2.

O objetivo foi verificar, nestes tipos de registros selecionados (D2, EF e DID), a ocorrência de mecanismos de indicação de gradação do aumentativo, se ela é marcada por mecanismo explícito ou implícito, quais são as frequências, as categorizações, considerando fatores linguísticos e extralinguísticos do contexto de enunciação.

Para o tratamento quantitativo dos dados analisados, foi utilizado o Programa GoldVarb X (2001), com intuito de obter resultados mais precisos e completos das frequências e ocorrências de categorizações. Esse programa foi idealizado por Steve Harlow e "tem como função indicar se os grupos de fatores da pesquisa são significativos ou não significativos e, em caso positivo, a hipótese será confirmada" (ARAÚJO, 2016, p. 63). Além disso, o programa é utilizado por pesquisadores da área de Sociolinguística, a fim de obter cálculos estatísticos e probabilísticos.

Para fazer a análise quantitativa dos dados por meio do GoldvarbX, foi necessário codificar todo corpus, conforme é requerido por este programa estatístico. Os códigos criados foram divididos em quatro grupos, sendo a variável dependente a expressão do aumentativo nos três tipos de contextos comunicativos os quais refletem as variáveis independentes aqui analisadas O primeiro grupo representou os tipos de registro (D2, DID e EF); o segundo indicou qual era o tipo de gradação, se era a gradação explícita, a implícita ou por meio de item lexical; o terceiro apontou exatamente a gradação ocorrida; e o último evidenciou a que classe de palavras o fenômeno pertence. Cada um desses grupos de fatores codificados correspondeu a uma coluna do programa e, então, os dados foram rodados. O resultado da rodagem já permite a análise dos dados, pois "ele informa a quantidade de ocorrências e os percentuais para cada variante em relação a cada fator considerado nos grupos de fatores" (OLIVEIRA, 2014, p. 15). 


\section{Análise e resultado da expressão do grau aumentativo}

Os dados da Tabela 1 totalizaram 737 ocorrências de indicação da expressão do grau aumentativo nos seis inquéritos analisados, sendo dois no contexto discursivo de diálogo entre duas pessoas (D2), dois de diálogo entre documentador e informante (DID) e dois de elocuções formais (EF).

Os recursos gradativos utilizados dividiram-se em gradação explícita, a qual se utiliza por meio de recursos gramaticais; gradação implícita, que é expressa através de pressupostos, subentendidos e gradação expressa por meio de item lexical, que é identificada pelo próprio item lexical que pode ser de base nocional ou de base gramatical ${ }^{1}$.

Tabela 1 - Tipos de gradação do aumentativo nos registros elocucionais

\begin{tabular}{|c|c|c|c|c|c|c|c|}
\hline \multirow{2}{*}{$\begin{array}{c}\text { TIPOS DE } \\
\text { GRADAÇÃO DO } \\
\text { AUMENTATIVO }\end{array}$} & \multicolumn{2}{|r|}{ D2 } & \multicolumn{2}{|r|}{ DID } & \multicolumn{2}{|r|}{ EF } & \multirow[b]{2}{*}{ TOTAL } \\
\hline & $\begin{array}{l}N^{0} \text { de } \\
\text { dados }\end{array}$ & Percentual & $\begin{array}{l}N^{0} \text { de } \\
\text { dados }\end{array}$ & Percentual & $\begin{array}{l}\mathrm{N}^{\circ} \text { de } \\
\text { dados }\end{array}$ & Percentual & \\
\hline Explícita & 97 & $33,8 \%$ & 122 & $42,5 \%$ & 68 & $23,7 \%$ & 287 \\
\hline Implícita & 77 & $31,8 \%$ & 99 & $40,9 \%$ & 66 & $27,3 \%$ & 242 \\
\hline $\begin{array}{l}\text { Por meio de } \\
\text { itens lexicais }\end{array}$ & 74 & $35,6 \%$ & 81 & $38,9 \%$ & 53 & $25,5 \%$ & 208 \\
\hline Total & 248 & $33,6 \%$ & 302 & $41,0 \%$ & 187 & $25,4 \%$ & 737 \\
\hline
\end{tabular}

A Tabela 1 mostra o total de 737 ocorrências na indicação de gradação no grau aumentativo nos seis inquéritos analisados, sendo 287 na gradação explícita, 242 na gradação implícita e 208 na gradação expressa por meio de itens lexicais.

Esses resultados apontam que, quando se consideram os três tipos de situações enunciativas, D2, DID e EF, verifica-se que a expressão da gradação foi mais frequente em Diálogos entre informante e documentador (DID), totalizando 302 dados, o que corresponde a $41 \%$ da totalidade das ocorrências.

Outra constatação que se faz é que há certo equilíbrio entre a utilização dos três recursos para indicar o aumentativo, mas a gradação explícita apresenta maior frequência e a expressão por meio de itens lexicais é a menos ocorrente, considerando os três tipos de situações enunciativas que compuseram o corpus.

1 A tabela deve ser lida de forma horizontal, para que se totalize a porcentagem. Os resultados representam os percentuais de ocorrência por tipos de registro (D2, DID e $\mathrm{EF})$. Essa metodologia de leitura se aplica a todas as tabelas. 
v. $7(2)$

414-432 ago/dez 2017

Ao analisar os dados, a gradação explícita (42,5\%) obteve maiores resultados no diálogo entre informante e documentador (DID). Por se tratar de entrevista, a hipótese que se levanta é que neste tipo de registro o entrevistado é mais formal e, consequentemente, emprega mais os mecanismos gramaticais explícitos quando deseja graduar algum item do enunciado que profere. A gradação explícita também foi significativa no diálogo entre duas pessoas (D2). Observa-se também que a gradação explícita foi mais marcada em situação dialógica $(33,8 \%)$ do que em elocuções formais.

É no diálogo entre documentador e informante (DID) que se constata uma preferência acentuada para expressar o aumentativo por meio de itens lexicais $(38,9 \%)$, em detrimento dos outros dois tipos de situações enunciativas. No caso, é o uso de palavras lexicais que expressam o grau aumentativo de base nocional e de base gramatical para indicar comparação, aumento ou intensificação durante o contexto discursivo.

Nos diálogos entre dois informantes (D2), e nas situações dialógicas entre informante e documentador (entrevista), que apresentaram a gradação explícita como mais frequente, observou-se, na análise do corpus, a necessidade do falante em enfatizar aspectos do conteúdo de sua fala, de modo explícito, ou seja, por meio de expedientes morfossintáticos. A hipótese é de que em situações dialógicas, por haver maior dinamicidade no processo de interação da fala ocasionado pelas mudanças de turnos, os falantes optam por marcar de modo explícito o aumentativo.

Quanto à gradação implícita, em relação aos três tipos de registros (D2, DID e EF), observa-se uma diferença considerável nos resultados. No DID, a gradação implícita foi de 40,9\%, destacando-se em comparação ao D2 (31,8\%) e ao EF (27,3\%).

Gradação explícita do aumentativo

O processo explícito de intensificação é indicado por meio de substantivos, adjetivos, verbos e advérbios de acordo com as gramáticas tradicionais, além de ser representado por meios morfológicos, sintáticos ou semânticos. Em adjetivos e advérbios, a gradação é expressa de forma comparativa e superlativa.

Os processos intensificadores de substantivos, adjetivos e advérbios podem ser encontrados no: 
1. Aumentativo

a. De forma sintética. Ex: "ele tranquilão né]" (D2: Inquérito $6)$;

b. De forma analítica. Ex: "o segundo volume teve uma grande evolução porque ele foi apresentado em cê-dê-rom esses atlas" (EF: Inquérito 1).

2. Comparativo

a. De superioridade. Ex: "eu ajudaria eles a estudar mais pra poder aprender e serem pessoas melhores do que eu no futuro" (DID: Inquérito 7);

b. De igualdade. Ex: "meu atlas foi apresentado tanto fonético quanto a parte semântico e lexical" (EF: Inquérito 1).

3. Superlativo

a. Relativo de superioridade. Ex: "a gente tinha falado era a parte mais eh: complexa um pouquinho do texto tá..." (EF: Inquérito 4);

b. Absoluto analítico. Ex: "eu fiquei muito feliz quando minha mãe engravidou né” (DID: Inquérito 3).

Tabela 2 - Frequência de gradação explícita

\begin{tabular}{|c|c|c|c|c|c|c|c|}
\hline \multirow{2}{*}{$\begin{array}{c}\text { GRADAÇÃo } \\
\text { EXPLÍ́CITA }\end{array}$} & \multicolumn{2}{|c|}{ D2 } & \multicolumn{2}{|c|}{ DID } & \multicolumn{2}{|c|}{ EF } & \multirow{2}{*}{ TOTAL } \\
\cline { 2 - 7 } & $\begin{array}{c}\text { No de } \\
\text { dados }\end{array}$ & Percentual & $\begin{array}{c}\text { No de } \\
\text { dados }\end{array}$ & Percentual & $\begin{array}{c}\text { No de } \\
\text { dados }\end{array}$ & Percentual & \\
\hline $\begin{array}{c}\text { Aumentativo } \\
\text { sintético }\end{array}$ & 10 & $50 \%$ & 4 & $20 \%$ & 6 & $30 \%$ & 20 \\
\hline $\begin{array}{c}\text { Comparativo } \\
\text { de igualdade }\end{array}$ & 1 & $14,2 \%$ & 3 & $42,9 \%$ & 3 & $42,9 \%$ & 7 \\
\hline $\begin{array}{c}\text { Superlativo } \\
\text { relativo de } \\
\text { superioridade }\end{array}$ & 26 & $31,3 \%$ & 31 & $37,4 \%$ & 26 & $31,3 \%$ & 83 \\
\hline $\begin{array}{c}\text { Superlativo } \\
\text { absoluto } \\
\text { analítico }\end{array}$ & 60 & $36,8 \%$ & 77 & $47,2 \%$ & 26 & $16,0 \%$ & 163 \\
\hline Total & 97 & $35,6 \%$ & 115 & $42,1 \%$ & 61 & $22,3 \%$ & 273 \\
\hline
\end{tabular}

De acordo com a Tabela 2, a maior ocorrência de gradação explícita aponta para o grau superlativo absoluto analítico (163 ocorrências) e o superlativo relativo de superioridade (83 ocorrências). Há ainda os demais tipos de graus os quais também são significativos, 
embora com valores menos expressivos, como o aumentativo sintético (20 ocorrências) e o comparativo de igualdade (7 ocorrências).

No que concerne aos contextos discursivos, foi relevante em D2 o grau aumentativo sintético (50\%). Nota-se que o grau aumentativo analítico, o comparativo de superioridade e o superlativo absoluto sintético não apresentaram um número de dados suficiente para possibilitar rodar o programa. Por isso, não constam na Tabela 2.

Em referência ao DID, o superlativo absoluto analítico obteve maior frequência, alcançando 47,2\%, despontando-se à frente do aumentativo sintético (20\%). Em EF, o comparativo de igualdade apresentou apenas três ocorrências. Um dos exemplos foi: "porque ele abrange tanto critérios da geolinguística quanto da sociolinguística e foi sistematicamente realizado" (EF: Inquérito 1).

Vale ressaltar que o superlativo absoluto analítico foi mais utilizado nos registros de DID (47,2\%) e de D2 (36,8\%). Nessas situações enunciativas, os informantes costumavam intensificar o que estava sendo dito, para destacar gradativamente com a expressão do aumentativo determinada informação do contexto. Por exemplo: "nos criamos juntos desde pequenininho eu cuidei muito dele quando ele era bebê" (DID: Inquérito 3) e "e aí como o serviço começou a crescer muito eu comecei a solicitá que eles contratassem outros fisioterapeuta" (D2: Inquérito 8). Na Tabela 2 fica evidente que o superlativo absoluto analítico não obteve destaque no contexto EF (16\%), quando comparado com os outros, mas, ainda assim, houve bastante dados significativos, assim como o superlativo relativo de superioridade $(31,3 \%)$.

Quanto aos temas dos inquéritos e à ocorrência do aumentativo, observou-se que, em um dos inquéritos de DID em que o tema era sobre casas em que morou na infância, um dos entrevistados empregou ricamente o aumentativo na descrição de uma casa. Foi o contexto de enunciação em que se obtiveram mais dados $(42,1 \%)$.

Nas elocuções formais, o corpus constituiu-se de duas aulas, ministradas na graduação, sobre os temas Dialetologia e Geografia. No caso, as expressões do aumentativo foram de 22,3\%. A hipótese é que nesse tipo de registro, que exige uma linguagem formal, menos emotiva, há uma menor ocorrência de expressão de aumentativo e, quando ocorre, a tendência é indicar a gradação por meio de item lexical para enfatizar parte do conteúdo da enunciação de modo mais produtivo, o que será visto mais adiante neste trabalho. 
Gradação implícita do aumentativo

Nos dados analisados, foi possível observar quatro tipos de gradação implícita na expressão do aumentativo. Isto quer dizer que são expressos indiretamente, ou seja, estão subentendidos pelo contexto.

Os processos de expressão do aumentativo por gradação implícita identificados no corpus analisado foram:

1. Na referência exofórica:

"[...] como esse ele tem uma lógica eh... que nós falamos nem sempre mas ele tem uma lógica mas deveria ter mas aqui ele tá falando de uma coisa que é até maior que é a lógica da sociedade" (EF: Inquérito 4).

Nesse processo de gradação implícita, utiliza-se de advérbios como marcador gramatical de argumentos ao se referir a algo que está no contexto extralinguístico. Além disso, utiliza de alguns advérbios para indicar o tempo, o lugar, a dimensão ou para exemplificar alguma coisa em relação ao meio externo.

2. Nas repetições (do significante):

a) De vocábulos. Ex: "IS:so isso isso isso quando chegá lá na linha dos duzentos metros quando era na curva nós parávamos (est: hum hum)" (D2: Inquérito 6);

b) De sintagmas ou orações. Ex: "esse capítulo ele só POde ser perfeitamente compreendido se vocês perfeitamente compreendido dentro da sequência que esse nosso autor propõe” (EF: Inquérito 4);

c) Por meio de paráfrases. Ex: "é sentir aquele carinho aquele amor aquela união... tudo assim a gente se sente bem melhor" (DID: Inquérito 3).

As repetições de vocábulos, de sintagmas ou orações e por meio de paráfrase, são empregadas para enfatizar o ponto de vista do falante que, operando com mecanismos de intensificação no contexto discurso, busca fortalecer a sua ideia, a fim de convencer o ouvinte. 
v. 7 (2) 414-432 ago/dez 2017

3. Na expressão intensificadora:

Ex: "então eh eu gosto... de tudo lá né... eu gosto de.... eu gosto mesmo é de ir pra Petró:polis" (D2: Inquérito 8).

Para aumentar o grau de expressividade, o falante salienta a informação ao ouvinte por meio de advérbios focalizadores, como: mesmo, até mesmo, exatamente, justamente, realmente etc. Às vezes, o falante emprega algumas estruturas cristalizadas, as quais pertencem ao léxico da língua e que já possuem um sentido familiar para os demais falantes.

\section{Na entonação:}

Ex: "nossos amigos nos ajudaram com as passagens com a festa do próprio casamento e: foi foi assim: parece que foi bem planejado" (DID: Inquérito 7).

A palavra assim, neste contexto, é entendida como "foi desse jeito mesmo". É pronunciada com entonação pausada e forte, instituída como parte da propriedade discursiva, da semântica de modalização e até mesmo da prosódica.

O número de dados desses processos de gradação implícita divide-se da seguinte forma:

Tabela 3- Frequência de gradação implícita

\begin{tabular}{|c|c|c|c|c|c|c|c|}
\hline \multirow{2}{*}{$\begin{array}{l}\text { GRADAÇÃO } \\
\text { IMPLÍCITA }\end{array}$} & \multicolumn{2}{|r|}{ D2 } & \multicolumn{2}{|r|}{ DID } & \multicolumn{2}{|r|}{ EF } & \multirow[b]{2}{*}{ TOTAL } \\
\hline & $\begin{array}{l}\mathrm{N}^{\circ} \text { de } \\
\text { dados }\end{array}$ & Percentual & $\begin{array}{l}\mathrm{N}^{0} \text { de } \\
\text { dados }\end{array}$ & Percentual & $\begin{array}{l}\mathrm{N}^{\circ} \text { de } \\
\text { dados }\end{array}$ & Percentual & \\
\hline $\begin{array}{c}\text { Referência } \\
\text { exofórica }\end{array}$ & 25 & $44,6 \%$ & 9 & $16,1 \%$ & 22 & $39,3 \%$ & 56 \\
\hline $\begin{array}{l}\text { Repetição de } \\
\text { vocábulos }\end{array}$ & 5 & $45,5 \%$ & 4 & $36,4 \%$ & 2 & $18,1 \%$ & 11 \\
\hline $\begin{array}{c}\text { Repetição de } \\
\text { sintagmas ou } \\
\text { orações }\end{array}$ & 6 & $42,9 \%$ & 2 & $14,2 \%$ & 6 & $42,9 \%$ & 14 \\
\hline $\begin{array}{c}\text { Repetição } \\
\text { por meio de } \\
\text { paráfrase }\end{array}$ & 4 & $30,8 \%$ & 7 & $53,8 \%$ & 2 & $15,4 \%$ & 13 \\
\hline $\begin{array}{c}\text { Expressão } \\
\text { intensificadora }\end{array}$ & 24 & $30,8 \%$ & 36 & $46,2 \%$ & 18 & $23,0 \%$ & 78 \\
\hline Entonação & 14 & $20,0 \%$ & 40 & $57,1 \%$ & 16 & $22,9 \%$ & 70 \\
\hline Total & 78 & $32,3 \%$ & 98 & $40,5 \%$ & 66 & $27,2 \%$ & 242 \\
\hline
\end{tabular}


Na Tabela 3, observa-se que a referência exofórica obteve 44,6\% de frequência em D2. Isso demonstra que, neste tipo de registro, é muito frequente a referência ao meio externo, empregando palavras e linguagem corporal. Pode-se notar que as elocuções formais (EF) também alcançaram dados importantes (39,3\%), visto que, em uma palestra ou em sala de aula, é relevante frisar o que está sendo dito através do meio extralinguístico, como por exemplo: "eu quero pegar aqui, num dos capítulos inicial uma expressão... que tem algumas expressões que são chaves aqui... que se eu fosse vocês eu destacaria" (EF: Inquérito 4). Nesse caso, o professor empregou o advérbio de lugar aqui para destacar palavras do texto ligadas a uma situação enunciativa específica.

Também no corpus analisado os recursos de repetições foram bastante ocorrentes. Sua ocorrência foi constatada nos três tipos de registros. Quanto à repetição de vocábulos, no tipo de registro D2, verificou-se maior ocorrência (45,5\%). Já na repetição de sintagmas ou orações, o resultado foi o mesmo, de $42,9 \%$ para D2 e EF. Entretanto, no DID, o percentual foi apenas de $14,2 \%$. Na repetição por meio de paráfrase, houve uma distinção significativa entre os três contextos discursivos, sendo maior em DID (53,8\%).

Outro processo de gradação implícita que os falantes empregam com muita frequência foi a expressão intensificadora, a qual obteve maior número de dados nos três tipos de registros, como se atesta na Tabela 3. Nos DID, a expressão intensificadora foi mais frequente, alcançando 46,2\%. Para explicar este resultado, a hipótese que se levanta é que, numa entrevista, o falante seleciona mecanismos para pôr em relevo seus sentimentos, para ratificar o que está dizendo, transmitir sua emoção em referência a algo que lhe traga boas ou más lembranças ou sentimentos. Por exemplo: "foi uma fase difícil na minha infância e: isso me deixou profundamente marcado nessa fase que infelizmente aconteceu" (DID: Inquérito 7).

A esse respeito, Castilho (2014, p. 557) explica que a expressão intensificadora, ao utilizar de modalizadores subjetivos discursivos "[põe] em relevo os sentimentos que são despertados no locutor diante do interlocutor, com respeito ao conteúdo sentencial". Numa entrevista, o falante se posiciona, intensifica suas ideias e demonstra seus sentimentos em relação àquilo que está sendo dito.

O recurso da entonação para indicar o aumentativo, nos diálogos entre o informante e o documentador (DID), obteve também destaque em relação aos outros tipos de registro. Sua ocorrência foi de 57,1\%, 
v. 7 (2)

414-432 ago/dez 2017

mostrando que esse é um importante recurso prosódico para expressar a gradação, empregado para exprimir a noção de grau. No D2, a gradação implícita de entonação teve a menor frequência (20\%), embora também tenha tido uma ocorrência significativa.

Gradação por meio de itens lexicais

Para Vieira e Vieira (2008, p. 75), a gradação expressa por meio de itens lexicais configura-se "pelo fato de a significação estar veiculada pelos traços semânticos presentes na constituição do próprio item lexical". Nesse caso, ela é autônoma, pois a expressão do grau não precisa de uma construção morfossintática, é o próprio radical que expõe o traço semântico e a sua intensificação.

As ocorrências de gradação por meio de itens lexicais podem ser de base nocional e de base gramatical.

1. Base nocional

a) Substantivo - "foi apresentado em noventa e quatro cês tão vendo esse monte de papel aqui" (EF: Inquérito 1).

b) Adjetivo - "ele chega aqui já não tem mais paciência e realmente tu tem um nível diferente" (D2: Inquérito 6).

c) Verbo - "com alguma coisa pra que ela continue crescendo reto então ah os filhos são assim mesmo..." (DID: Inquérito 7).

Tabela 4 - Gradação de aumentativo por itens lexicais de base nocional

\begin{tabular}{|c|c|c|c|c|c|c|c|}
\hline \multirow{2}{*}{$\begin{array}{c}\text { BASE } \\
\text { NOCIONAL }\end{array}$} & \multicolumn{2}{|r|}{ D2 } & \multicolumn{2}{|r|}{ DID } & \multicolumn{2}{|r|}{ EF } & \multirow[b]{2}{*}{ TOTAL } \\
\hline & $\begin{array}{l}\mathrm{N}^{0} \text { de } \\
\text { dados }\end{array}$ & Percentual & $\begin{array}{l}\mathrm{N}^{\circ} \text { de } \\
\text { dados }\end{array}$ & Percentual & $\begin{array}{l}\text { No de }^{\circ} \\
\text { dados }\end{array}$ & Percentual & \\
\hline Substantivo & 18 & $40,9 \%$ & 12 & $27,3 \%$ & 14 & $31,8 \%$ & 44 \\
\hline Adjetivo & 3 & $23,1 \%$ & 4 & $30,7 \%$ & 6 & $46,2 \%$ & 13 \\
\hline Verbo & 6 & $50,0 \%$ & 5 & $41,7 \%$ & 1 & $8,3 \%$ & 12 \\
\hline Total & 27 & $39,2 \%$ & 21 & $30,4 \%$ & 21 & $30,4 \%$ & 69 \\
\hline
\end{tabular}

A gradação expressa por meio de itens lexicais de base nocional obteve resultados consideráveis no que concerne à ocorrência de substantivo nos três tipos de registros, quando comparado aos adjetivos e aos verbos. Nos D2, a ocorrência de substantivo foi maior que em DID e EF. 
2. Base Gramatical:

a) Todo/tudo: "não moro com eles eu moro com minha avó todo dia estou em contato com eles" (DID: Inquérito 3).

b) Sempre/nunca: "é porque ele sempre traz pra mim... é [muito bom né?" (D2: Inquérito 8).

Tabela 5 - Gradação do aumentativo por itens lexicais de base gramatical

\begin{tabular}{|c|c|c|c|c|c|c|c|}
\hline \multirow{2}{*}{$\begin{array}{c}\text { BASE } \\
\text { GRAMATICAL }\end{array}$} & \multicolumn{2}{|r|}{ D2 } & \multicolumn{2}{|r|}{ DID } & \multicolumn{2}{|r|}{ EF } & \multirow[b]{2}{*}{ TOTAL } \\
\hline & $\begin{array}{l}N^{\circ} \text { de } \\
\text { dados }\end{array}$ & Percentual & $\begin{array}{l}N^{\circ} \text { de } \\
\text { dados }\end{array}$ & Percentual & $\begin{array}{l}\mathrm{N}^{0} \text { de } \\
\text { dados }\end{array}$ & Percentual & \\
\hline $\begin{array}{c}\text { Base } \\
\text { gramatical } \\
\text { todo/tudo }\end{array}$ & 36 & $43,4 \%$ & 21 & $25,3 \%$ & 26 & $31,3 \%$ & 83 \\
\hline $\begin{array}{c}\text { Base } \\
\text { gramatical } \\
\text { sempre/nunca }\end{array}$ & 11 & $21,6 \%$ & 38 & $74,5 \%$ & 2 & $3,9 \%$ & 51 \\
\hline Total & 47 & $35,0 \%$ & 59 & $44,0 \%$ & 28 & $21,0 \%$ & 134 \\
\hline
\end{tabular}

Como o objetivo desta pesquisa foi estudar a expressão do aumentativo, essas duas bases gramaticais apresentadas na Tabela 5 foram as que transmitiram a intensificação de gradação nos contextos discursivos analisados. A partir do corpus analisado, a gradação em itens lexicais de base gramatical todo/tudo no contexto D2 (43,4\%) destacouse consideravelmente em comparação com os outros tipos de registro. A base gramatical sempre/nunca foi mais produtiva no tipo de registro $\operatorname{DID}(74,5 \%)$.

Constata-se que esses dois tipos de bases gramaticais estão muito presentes no discurso cotidiano dos falantes e trazem uma carga semântica muito forte para intensificar, enfatizar, destacar algo ou alguma coisa do conteúdo sentencial.

A seguir, apresenta-se a tabela da classe de palavras empregadas como recurso para expressar o aumentativo, a fim de identificar como o falante faz esta seleção e em que tipos de registros são mais frequentes. 
v. 7 (2)

414-432 ago/dez 2017
Tabela 6 - Frequência de classes de palavras na expressão do aumentativo

\begin{tabular}{|c|c|c|c|c|c|c|c|}
\hline \multirow{2}{*}{$\begin{array}{c}\text { CLASSES } \\
\text { DE } \\
\text { PALAVRA }\end{array}$} & \multicolumn{2}{|r|}{ D2 } & \multicolumn{2}{|r|}{ DID } & \multicolumn{2}{|r|}{ EF } & \multirow[b]{2}{*}{ TOTAL } \\
\hline & $\begin{array}{l}\mathrm{N}^{0} \text { de } \\
\text { dados }\end{array}$ & Percentual & $\begin{array}{l}\mathrm{N}^{\mathbf{0}} \text { de } \\
\text { dados }\end{array}$ & Percentual & $\begin{array}{l}N^{0} \text { de } \\
\text { dados }\end{array}$ & Percentual & \\
\hline Substantivo & 51 & $34,7 \%$ & 44 & $29,9 \%$ & 52 & $35,4 \%$ & 147 \\
\hline Adjetivo & 85 & $30,2 \%$ & 136 & $48,4 \%$ & 60 & $21,4 \%$ & 281 \\
\hline Advérbio & 76 & $35,0 \%$ & 82 & $37,8 \%$ & 59 & $27,2 \%$ & 217 \\
\hline Verbo & 34 & $41,5 \%$ & 38 & $46,3 \%$ & 10 & $12,2 \%$ & 82 \\
\hline $\begin{array}{l}\text { Ausência de } \\
\text { classe }\end{array}$ & 3 & $27,3 \%$ & 2 & $18,2 \%$ & 6 & $54,5 \%$ & 11 \\
\hline Total & 240 & $32,6 \%$ & 294 & $39,9 \%$ & 203 & $27,5 \%$ & 737 \\
\hline
\end{tabular}

De acordo com a Tabela 6, o adjetivo foi o mais frequente, obtendo 281 ocorrências. A classe de adjetivo foi mais utilizada no tipo de registro DID $(48,4 \%)$ comparada com os outros contextos enunciativos, pois 0 falante tende a utilizar a gradação explícita para enfatizar suas ideias, suas opiniões e ao falar sobre si mesmo, como no exemplo: "muito bom mesmo pelo fato deles terem se separado e eu ter ficado com a minha avó mas nunca perdemos contato minha mãe e meu pai sempre estão muito presentes em minha vida" (DID: Inquérito 3/Gradação explícita superlativo absoluto analítico adjetivo).

A classe de advérbio também apresenta dados relevantes, sendo o segundo predominante na pesquisa, com 217 ocorrências. Segundo a Tabela 6, o advérbio se destacou também no tipo de registro DID $(37,8 \%)$ e no tipo de registro D2 (35\%), com uma pequena diferença.

Nas elocuções formais (EF), o substantivo obteve mais ocorrências $(35,4 \%)$ quando comparado com os outros tipos de registro, mas com uma diferença mínima em relação ao D2 (34,7\%). Além disso, a EF obteve dados significativos na ausência de classe com 54,5\% novamente comparado com os outros contextos discursivos, ou seja, o falante buscou outros meios para expressar a gradação como nessa frase que foi selecionada da análise: "na verdade sobretudo quanto mais nos afastamos do (inint.) é um mundo pouquíssimo urbanizado então basicamente ruralizado e dentro desse mundo cultural" (EF: Inquérito 4).

\section{Considerações finais}

Este trabalho buscou analisar a expressão do aumentativo na fala manauara de modo aprofundado a fim de investigar em qual dos três tipos de registros (D2, DID e EF), coletados no banco de dados do FAMAC 
(Fala Manauara Culta e Coloquial), predominou a gradação explícita, implícita e indicadas por itens lexicais. A gradação do aumentativo predominou no tipo de registro DID com 41\% de frequência. A gradação explícita obteve o número de dados maior em todos os tipos de registro, seguido da gradação implícita e por meio itens lexicais. Os menores percentuais, em relação aos tipos de gradação, ocorreram nas elocuções formais (EF). Os resultados obtidos mostraram que a gradação é significativa e atua no cotidiano do falante, principalmente quando ele tem a intenção de destacar algo usando os recursos gramaticais, prosódicos ou semânticos durante uma conversa entre amigos, uma entrevista, em uma aula ou palestra.

O grau avaliativo esteve presente em todas as modalidades analisadas, de modo que o falante exprimiu a afetividade, manifestou um julgamento sobre algo e também utilizou o grau para associar o tamanho de alguma coisa. Além disso, na gradação se verificou a indicação de força e/ou foco empregado no sentido mais amplo e foi realizado por meio de vários recursos léxico-gramaticais e por categorias semânticas prototípicas para graduar qualidades, entre outros.

\section{Referências}

ARAÚJO, J. M. O. de. A expressão de futuridade na escrita jornalística manauara dos anos 80 aos dias atuais: um estudo sociofuncionalista. Manaus: UEA, 2016.

BECHARA, E. Moderna gramática portuguesa. 37 ed. ver. ampl. Rio de Janeiro: Lucerna, 2001.

CALVET, L. Sociolinguística: uma introdução crítica. São Paulo: Parábola Editorial, 2002. Tradução por Marcos Marcionilo.

CASTILHO, A. T. de. Nova gramática do português brasileiro. 1 ed., $3^{\text {a }}$ reimpressão. São Paulo: Contexto, 2014.

CEGALLA, D. P. Novíssima gramática da língua portuguesa. 48 ed. ver. São Paulo: Companhia Editora Nacional, 2008.

CUNHA, A. F. Funcionalismo. In: MARTELOTTA, M. E. Manual de Linguística. São Paulo: Contexto, 2011.

LABOV, W. Padrões Sociolinguísticos. São Paulo: Parábola Editorial, 2008. Tradução Marcos Bagno, Maria Marta Pereira Scherre e Caroline Rodrigues de Oliveira.

MARTIN, J. R.; WHITE, P. The language of evaluation: appraisal in English. London: Palgrave, 2005.

MARTINS, S. A. Macroprojeto Estudo da Variedade Urbana Oral Culta de Manaus. Manaus: NEPLAE, 2009. 
v. $7(2)$ 414-432 ago/dez 2017

MEDEIROS, A. B. Sobre aumentativos de verbos. ReVEL, v. 13, n. 24, 2015.

OLIVEIRA, J. M. de. MINICURSO: introdução ao GoldVarbX: uso e interpretação. Paraíba, 2014.

ROCHA, L. C. de A. Estruturas morfológicas do português. 2. ed. São Paulo: WMF Martins Fontes, 2008.

SOUZA, E. R. Funcionalismo Linguístico: novas tendências teóricas. São Paulo: Contexto, 2012.

VIAN JÚNIOR, O.; SOUZA, A. A. de.; ALMEIDA, F. A. S. D. P. (Org.). A linguagem da avaliação em língua portuguesa: estudos sistêmico-funcionais com base no sistema da avaliatividade. São Carlos: Pedro \& João Editores, 2010.

VIEIRA, S. R.; VIEIRA, M. dos S. M. A expressão de grau: para além da morfologia. Cadernos de Letras da UFF - Dossiê: Literatura, Língua e Sociedade, n. 34, p. 63-83, 2008.

Recebido em: 4 de fev. de 2017.

Aceito em: 5 de jun. de 2017. 